\title{
NASA pins hopes on nuclear-powered orbiter
}

Tony Reichhardt, Washington

Daring, scientifically rewarding but fraught with technical and political risk. That's the way many space scientists view a proposed nuclear-powered Jupiter mission that would be the most capable - and probably the most expensive - planetary spacecraft ever launched by NASA.

The Jupiter Icy Moons Orbiter concept was unveiled earlier this month as part of NASA's budget request for 2004. Slated for launch no earlier than 2011, the orbiter is the centrepiece of Project Prometheus, a multibillion-dollar effort to develop nuclear power and propulsion for deep-space exploration. The planned budget for the orbiter alone would exceed $\$ 90$ million next year. Sources in Congress suggest that the total budget needed to launch the spacecraft could run to $\$ 4$ billion.

The orbiter's nuclear reactor would power an ion-drive engine: a device that expels ionized gas at high velocities to produce a small but continuous thrust. In weight terms, nuclear-powered thrusters are more fuel-efficient than those that use conventional chemical fuels. This would allow the orbiter to perform manoeuvres such as orbiting three of Jupiter's moons in succession. The orbiter is intended to circle three satellites - Europa, Ganymede and Callisto — for months at a time, seeking evidence of oceans beneath their icy surfaces.

Using a nuclear reactor also greatly

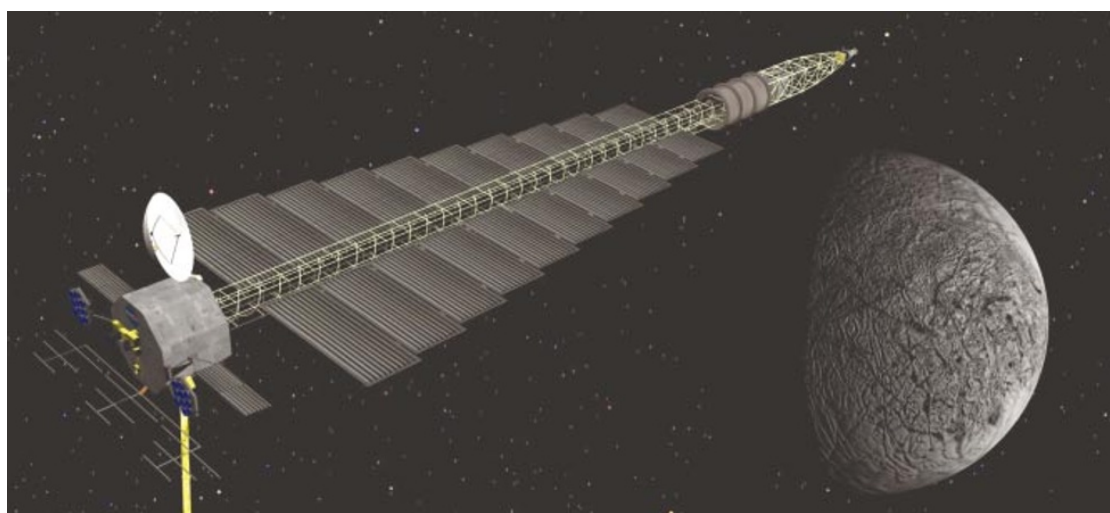

High flier: NASA's planned orbiter for Jupiter's moons could revolutionize planetary exploration.

increases the on-board power. The Cassini spacecraft, en route to Saturn, has about 875 watts of power on board. A nuclear reactor could produce tens of kilowatts. "This changes the entire regime of science experiments," says Colleen Hartman, head of the Solar System exploration division at NASA's headquarters in Washington. More powerful ice-penetrating radars could be flown and more data sent back to Earth.

NASA faces many hurdles if these benefits are to be realized. The agency has never launched a space-based nuclear reactor, for example. Keeping the reactor away from the scientific instruments may dictate a different shape for the orbiter, and NASA will have to learn how to stabilize and manoeuvre such a spacecraft. Public protests have accompanied the previous launches of spacecraft carrying small amounts of nuclear material (see Nature 410, 626; 2001), and the Columbia accident has enhanced fears over safety.

NASA will also have to convince Congress that the mission is worth $\$ 4$ billion. Advocates of planetary exploration say that nuclear propulsion is the best option, and that a similar system could be used on other missions if the orbiter is successful. But Louis Friedman, executive director of the Planetary Society in Pasadena, California, points out that if the project runs into problems, Europa exploration - a high priority for planetary scientists - could take longer than if conventional propulsion were used.

\section{Europe draws up plans for funding agency}

\section{Marieke Degen, Munich}

The future of science in the European Union (EU) began to take shape last week, as plans for a new basic-research funding agency gained momentum.

A high-level expert group met for the first time on 19 February in Paris, charged with outlining options for the creation of a European Research Council (ERC). The need for an independent, multidisciplinary agency has been intensively discussed during the past six months, after a meeting of scientists and research managers hosted by the Danish Research Councils (see Nature 419, 108-109; 2002). Advocates argue that the council is needed to close the gap between the quality of basic science in Europe and in the United States. It would complement the EU's E17.5-billion (US\$18.8-billion) application-oriented Framework Programme.

Members of the ERC expert group, which consists of national research-council heads and other science administrators, left most details unconfirmed, but agreed on basic principles. Delegates said that the council should not become political and should be committed to scientific excellence, rather than ensuring that each country receives as much back as it puts in.

The council's structure, size and funding mechanisms have yet to be defined. In particular, it is unclear to what extent any new agency will redistribute funds from existing EU and national research programmes, or how much fresh money it is likely to bring in. Discussions at the meeting about the council's budget covered figures from hundreds of millions to tens of billions of euros.

The idea has the strong backing of at least one section of the research community. Some $\mathbf{3 0 0}$ leading life scientists and representatives of national funding agencies held an independent meeting after the expert-group gathering, to discuss the planned council. Frank Gannon, director of the European Molecular Biology
Organization in Heidelberg, Germany, who helped to organize the second meeting, says that the council should focus on funding basic, investigator-driven research and supporting research infrastructure.

The expert group will refine its plans over the next few months and consult researchers outside the life sciences.

"It is important that scientists give us a feeling of what they need, and of which areas they think the council should cover," says Mogens Flensted-Jensen, vice-chairman of the Danish Research Councils and a member of the expert group. "But it is equally important to bring the ERC to the political agenda without further delay. Our task now is to work out a concrete proposal for how to launch it as soon as possible."

According to optimistic predictions, the council could come into being as early as 2004, when the Republic of Ireland takes over presidency of the EU, followed by the Netherlands. Both countries are expected to support the initiative. 